Portland State University

PDXScholar

$11-28-2021$

\title{
Bridging the Gap Between Clients and Public Defenders: Introducing a Structured Shadow Method to Examine Attorney Communication
}

Christopher M. Campbell

Portland State University, cmc22@pdx.edu

Kelsey S. Henderson

Portland State University, khender2@pdx.edu

Follow this and additional works at: https://pdxscholar.library.pdx.edu/ccj_fac

Part of the Criminology Commons

Let us know how access to this document benefits you.

\section{Citation Details}

Campbell, Christopher M. and Henderson, Kelsey S., "Bridging the Gap Between Clients and Public Defenders: Introducing a Structured Shadow Method to Examine Attorney Communication" (2021). Criminology and Criminal Justice Faculty Publications and Presentations. 103.

https://pdxscholar.library.pdx.edu/ccj_fac/103

This Pre-Print is brought to you for free and open access. It has been accepted for inclusion in Criminology and Criminal Justice Faculty Publications and Presentations by an authorized administrator of PDXScholar. Please contact us if we can make this document more accessible: pdxscholar@pdx.edu. 
Bridging the gap between clients and public defenders:

Introducing a structured shadow method to examine attorney communication

Christopher Campbell, Ph.D.

Kelsey Henderson, Ph.D.

Christopher M. Campbell, Department of Criminology \& Criminal Justice, Portland State University; Kelsey S. Henderson, Department of Criminology \& Criminal Justice, Portland State University

Correspondence concerning this article should be address to Christopher Campbell, Department of Criminology \& Criminal Justice, Portland State University, 506 SW Mill St., P.O. Box 751, Portland, OR, 97201. E-mail: ccampbbell@pdx.edu

Acknowledgments

The authors would like to thank Megan Mohler, Leah Reddy, and Kayla LaBranche for their help in this project, and to Professor Janet Moore and Dr. Marla Sandys for their valuable feedback during this process.

Declaration of Interest Statement

No potential conflict of interest was reported by the authors.

This paper is not the copy of record and may not exactly replicate the final, authoritative version of the article. The final article will be available, upon publication, via https://doi.org/10.1080/0098261X.2021.2011494 
In the United States, the vast majority of criminal defendants are indigent, with approximately $82 \%$ of felony defendants in large, state courts represented by public defenders (Harlow, 2000). Given this dependence on public defense services, conceptualizing effective representation beyond the guidelines of Gideon v. Wainwright (1963) is an increasingly important task; one that is crucial for improving the public defense system specifically, and the criminal justice system more generally (e.g., Steinberg, 2013). However, the obstacles to an effective attorney-client relationship are plentiful and complex. Public defenders face a unique set of challenges, not likely to be as pervasive for privately-retained attorneys. One of the biggest challenges is a lack of trust between the client and their attorney, often depicted in a trope by defendants as the "public pretender" (Drinan, 2010; Moore \& Davies, 2016). Waning or nonexistent trust has the potential to hinder open communication, and negatively impact the attorney-client relationship (Boccaccini \& Brodsky, 2002). Understanding the factors, such as trust, that contribute to effective attorney-client communication in public defense is particularly important considering these attorneys are often overworked and underfunded (American Bar Association, 2004), although little research has examined this relationship thus far (Moore et al., 2018).

Recent research has emphasized greater need for a client-centered approach to lawyering (Beeman, 2018), which can contribute to a more effective relationship between clients and their attorneys. One key component of an effective attorney-client relationship, and the focus of this paper, is communication (e.g., listening or asking for the client's opinion). Research has begun to focus more extensively on the communication aspect of the attorney-client relationship between clients and public defenders, and sheds light on defendants' perceptions of factors that influence the relationship. This research suggests small meaningful changes can contribute to a more positive 
interaction (e.g., avoiding tendencies to interrupt the client; Barton et al., 2006). In spite of the growing recognition of communication's importance to the attorney-client relationship, reliably and validly capturing such nuance in a sensitive area (i.e., attorney-client privilege) has rarely been feasible. This project aims to provide methodological tools for researchers, practitioners, and lawyers to measure these factors to further examine factors that are important for effective attorneyclient communication.

Few studies have examined attorney-client communication in public defense, and most rely on role-playing by non-lawyers or post hoc surveys about experiences (Moore et al., 2018). Even fewer engage in direct observation of the attorney-client interaction. Observing these interactions directly is an advantageous method, however, it must be done carefully considering the labyrinth of ethical and legal challenges (Moore et al., 2018). Below, we present the development and demonstration of an innovative, exploratory approach to understanding and directly observing attorney-client communication while also collecting information from both the attorneys' and clients' perspectives. The project involved two unique phases. The first phase is a survey of public defenders that captures attorneys' perspectives of what factors are important in developing and maintaining good communication with clients. The second phase involves two subsets, we call Phase II-Part A and Phase II-Part B. Phase II-A is an exploratory method of shadowing attorneys in meetings with their clients to identify if such factors are present. Last, Phase II-B involves a survey of clients to assess the importance of these factors from their vantagepoint and their overall perception of communication with their attorney.

As the Supreme Court recently acknowledged the importance of attorney-client communication (Missouri v. Frye, 2012; Padilla v. Kentucky, 2010), and both defenders and clients alike share concerns regarding the quality of communication, research on this topic is 
crucial, especially those that use methodologies that take into consideration both attorneys' and clients' perspectives. Below, we briefly discuss key findings from research on attorney-client communication, while simultaneously highlighting the various methodologies used to generate those findings, which will lead into a discussion of the structured shadow methodology demonstrated in this project.

\section{Prior Research on Attorney-client Communication}

It has been long suggested by attorneys and researchers alike that the performance of defense attorneys ought to be judged on the basis of their knowledge and lawyering skills, not solely the merit of the outcome (discussed in Boccaccini \& Brodsky, 2002). Particularly, defense attorneys are often judged on the ability to secure a favorable outcome at trial, or obtain a more favorable deal than what was initially offered by the prosecution. However, recent research has begun to highlight the importance of other aspects of the attorney-client relationship that may be just as important as the outcome (Boccaccini \& Brodsky, 2002; Boccaccini et al., 2004). A growing body of empirical evidence supports the notion that quality communication can contribute to positive attorney-client relationships, which is a necessary component for providing quality representation.

\section{Interviews and Surveys of Defendants}

Boccaccini and Brodsky (2001) provided surveys to 250 male Arkansas adults in custody (AIC) to examine perceptions of their most recent experience with their defense attorneys. Respondents were asked to describe attributes of an "ideal" defense attorney. The responses largely fell into one of three categories: loyalty (commitment to defendant's case and interests), lawyering skills (knowledgeable about the law and effective deal-maker), and client-relation skills (being honest, supportive, and spending time listening to the defendant's concerns). In conjunction 
with these responses, participants noted that they would be more likely to cooperate with this “ideal" attorney, as well as be more open, honest, and upfront with communicating information.

These findings regarding communication were further supported in a second study surveying 252 defense attorneys and 103 AIC in Alabama (Boccaccini et al., 2004). All respondents were asked to rate the importance of 13 lawyering skills, of which seven were clientrelation skills and six were legal skills. Clients who are were allowed/asked to participate in the attorney-client relationship reported greater levels of trust in their attorney, and trust was associated with higher levels of satisfaction with one's attorney. Some of the top-rated (ranked as very important or essential) client-relationship skills involved communication, such as keeping clients informed about their case (31\% of attorneys and $42 \%$ of AICs endorsed), involving clients in decisions (34\% of attorneys and $41 \%$ of AICs), and listening to clients (62\% of attorneys and $35 \%$ of AICs).

More recent research revisited the importance of such communication factors and how client perceptions of their defense attorney might relate to satisfaction. Campbell and colleagues (2015) investigated the importance of five key factors that public defense attorneys should address that may prove to be very important in obtaining client satisfaction and cooperation. Assessing 156 survey responses from past clients in Hamilton County (Cincinnati), Ohio, it was found that client satisfaction and perceptions of the process (Campbell et al., 2015) were strongly associated with how well attorneys asked the client his/her opinion, listened to the client, focused on the client's case during meetings, and informed the client of potential consequences. These findings were supported by an open-ended focus group discussion with seven former clients of the Hamilton County Public Defender's office, who emphasized the importance of communication, largely in knowing what is happening with the case and possible consequences. Collectively, these 
findings demonstrate how the client's perception (e.g., in being allowed their voice in the process) and level of satisfaction should be considered in addition to more traditional case outcome measures (Sandys \& Pruss, 2017).

In one of the most in-depth examinations to date, Sandys and Pruss (2017) interviewed 120 clients of public defenders in Indiana, both at the beginning of their case and after it had been resolved. Clients were generally satisfied with their public defender and satisfaction correlated with indicators of communication (e.g., "my lawyer says confusing things"), investigation (e.g., “my lawyer does what s/he says they will”), and advocacy (e.g., "I feel like my attorney is on my side"). As the authors point out, while advocacy and investigation are skills generally addressed in clinics/law school (i.e., legal skills), training in interpersonal communication skills are less likely to be taught, yet still important. Specific to attorney-client communication, six factors of communication were found to contribute to client satisfaction. They involve whether the lawyer (1) said confusing things, (2) explained what was going to happen next, (3) treated the client with respect, (4) interrupted the client, (5) told the client what they are planning to do, and (6) actually followed through on what they said they would (Sandys \& Pruss, 2017). This research suggests the lawyer's interpersonal skills, their words, and actions, can be just as influential as their knowledge of the law and ability to generate favorable case outcomes.

Most recently, Moore and colleagues (2019) conducted 22 interviews with public defense clients in an effort to identify more nuanced expectations regarding quality communication. Among their findings, participants emphasized the importance of communication content (i.e., information sharing, providing the client with voice, and empathy for the client), and the timing of the communication (i.e., at what point in the process, the frequency and duration of contact). Much of the findings related to information sharing were consistent with Sandys and Pruss (2017), 
highlighting the importance of discussion on court proceedings, what happens next, possible consequences, and how attorneys are working to help the client. Each of these were found to be key points that clients expected their attorneys to make clear.

Although interviews with defendants (and attorneys) provide valuable information regarding their perspectives and attitudes, it cannot provide insight into how individuals react to others, their actions that come from anticipating and interpreting the actions of others, and the dynamic, rather than static nature of relationships (Clair, 2020). Additional concerns surrounding issues in memory-recall, ability to articulate beliefs and values, and threats of social desirability bias affect survey and interview data. Below we discuss research findings on the attorney-client relationship gathered through observational methods, and the benefits of such methodologies.

\section{Direct Observation of Attorney-client Interaction}

Beyond these studies, there is little information in terms of quality communication as observable, measurable components in the United States. There have been only a few studies since the 1960s have attempted direct observation of attorney-client interactions, and most only view the quality of communication a secondary aim behind content or law (e.g., Sudnow, 1965). Many of the direct observation efforts were concentrated in civil settings, where studies examined attorney-client interactions in a clinic for student legal services (Goldsmith, 1980), in divorce cases (Sarat \& Felstiner, 1989), bankruptcy cases (Neustadter, 1986), and a disability rights clinic (Gellhorn et al., 1994). A common finding across the studies was the recognition of a perpetual power struggle between the attorney and the client, which typically played out in the form of conversation dominance. Similarly, Sarat and Felstiner (1989) in their observation of 115 attorneyclient divorce conferences from California and Massachusetts, demonstrated that attorneys often focus the discussion on rules, procedures, and jargon, which can cloud the client's understanding 
of the process. While the findings from these studies further bolster the importance of communication between attorneys and their clients, they do not emphasize how such communication can impact the dynamic between disadvantaged clients and particularly not in a public defense setting.

Although even more sparse than in the civil settings, a few research efforts have focused on direct observations of attorney-client interactions among people from socioeconomic disadvantage (Clair, 2020; Hosticka, 1979) and among public defenders (Clair, 2020; Cunningham \& McElhinny, 1995; Gonzalez Van Cleve, 2017; Sudnow, 1965). These findings align with those of studies previously discussed. For example, Hosticka (1978) observed almost 50 interactions where lawyers interrupted their client an average of 10.4 times per interview, which equated to an interruption every three minutes. Another common thread that emerged from more recent observations is the recognition that public defenders often must work on the side of brevity, which plays into the power struggle and interruptions. Public defenders move quickly in navigating case conversations (often due to low resources and high caseloads) and legitimacy among the courtroom workgroup, but such dialogue leads to closed-ended questions, interruptions, and at times a dehumanizing demeanor (Gonzalez Van Cleve, 2017; Sudnow, 1965). In a systematic, interdisciplinary effort of directly observing attorney-client interactions for the purpose of gauging communication, Cunningham and McElhinny (1995) reported on a pilot study in which they analyzed the observed interactions using sociolinguistics. Their findings highlighted the importance of nonverbal communication, providing context to decisions, minimizing jargon, providing voice to the client, and avoiding interruptions in the dialogue (Cunningham \& McElhinny, 1995, p. 312). 
More recently, Gonzalez Van Cleve (2017) and Clair (2020) analyzed how race and class inform the attorney-client relationship. Clerking for public defenders, and following them in their day-to-day operations, Gonzalez Van Cleve's ethnography provided insight into how public defenders must learn to code-switch depending on their audience (e.g., courtroom workgroup versus clients). Moreover, the defenders must act as ambassadors of a racialized system as they weigh the going rate of cases and calculate the worth of zealous defense, which would often coincide with the client's disadvantaged background. Providing further insight to this dynamic was Clair's (2020) qualitative approach involving interviews of defendants and lawyers (2020), court proceeding observations, and via shadowing three public defenders (including interactions between defenders and clients) in the Boston area. Clair's (2020) work provided compelling accounts of how the privileged versus the disadvantaged approach their defense attorney (e.g., the privileged are more likely to delegate to their attorney's expertise, not having experienced mistreatment by the courts and law enforcement before), and how the court rewards the behaviors (i.e., delegation, speaking through one's attorney) most likely to be exhibited by those coming from a privileged background. The richness of these data could not be generated from solely interviews or observing court proceedings, rather observing interactions between client and counsel allows researchers to make more reliable claims about these relationships and situational behaviors (as discussed in Clair, 2020, p. 200). In short, all methodologies pose advantages and drawbacks; as such, when examining a dynamic phenomenon involving individual relationships (such as attorney-client communication), a mixed-method approach using triangulation of data sources is preferred.

\section{Bedside Manner and Informing Professionalism in Criminal Justice}


Focusing on the reform of attorney-client communication parallels movements in professionalism seen in both other aspects of the justice system, as well as in the medical field. Criminal justice reform in the last few decades of the twentieth century was often characterized by a movement of professionalism, be it in policing (Sklansky, 2011) corrections (Kohnke, 2001), and courts (Gerber, 1989). Efforts to increase professionalism, which often varied widely, tend to involve structuring discretion and creating more guiding policy (see Davis, 1976; Walker, 1993). One aspect of professionalism often slow to develop in positions with high degrees of discretion (e.g., patrol officers and attorneys) is communication; compared to medicine and other fields, the criminal justice system falls behind in conducting and using research on effective communication (Moore et al., 2018). While professionalism was beginning to take hold in criminal justice, a similar, yet older movement was re-shaping the field of medicine.

Much like the professionalism movement of criminal justice agencies (in regards to "clients"), over the last 20 years the medical profession has undertaken a new approach to professionalism with regard to the patient. Today doctors interact with patients more than ever before, emphasizing the need for continued evaluation and improvement of patient-centered care (Institute of Medicine [IOM], 2001). Much of the reasons for the shift was due to the failed assumption that patient input and satisfaction had no influence on the clinical outcome (IOM, 2001). Not only has satisfaction since been linked to better clinical outcomes, but through many evaluations the shift to patient-centered care has been shown to improve patient satisfaction with healthcare, increase the patient's willingness to accept medical opinions given, and decrease the overuse and underuse of medical resources (Agency for Healthcare Research and Quality, 2005; Shaller, 2007; Stewart et al., 2000). One method used to achieve such positive results was the improvement of bedside manner, which was shown to decrease diagnosis biases and a reduce error 
rates (Hoff, Pohl \& Bartfield, 2006). This advancement in patient-centered care was largely dependent on discourse analysis (i.e., analyzing conversations), which involves direct observations of doctor-patient conversations, or audio or video-recordings, and using them as teaching tools (Smith, 2018). Similar methodologies have been suggested as useful tools for examining and improving attorney-client communication skills (see Smith, 2018).

A great deal of focus has been given to patient satisfaction in the medical field, and less to client satisfaction in the legal field, which is surprising given the similarities in the doctor-patient and attorney-client relationships (e.g., privilege of communication; Sandys \& Pruss, 2017). Drawing directly from these advancements in the medical field, the crucial connectivity between clients and public defenders becomes clear (see Cunningham, 1998). Similar to patients in the medical field, it was assumed that clients' satisfaction focused on their case outcome; however, more recent research demonstrates that defendants are just as concerned about their lawyers' interpersonal skills and being involved in the process (Boccaccini \& Brodsky, 2002; Boccaccini et al., 2004; Moore et al., 2019). For a defense attorney, when developing a "bedside manner" within the attorney-client relationship, biases may be dispelled while contextual dynamics drive the relationship forward. In other words, if the attorney is more astute to the needs of the client, then a more cooperative working relationship will be fostered. Similarly, adopting a method of relaying client's rights and expectations for adequate defense can be expected to yield better process outcomes and improved attorney-client relations. Within the attorney-client relationship, seeking more efficient ways of creating cooperation, providing advice and alternatives, and striving for effective and efficient communication should continue to be explored empirically to better afford public defenders with the tools required to foster an effective relationship with their 
clients. We drew on this research from the medical field, in additional to the legal field, to create checklist items for the current study (more information on this checklist below).

\section{The Current Study}

Given that research is limited on conceptualizing and operationalizing quality communication, one of the goals of our project was to address this important missing link in measurement. Until more recently (see Clair, 2020), in the direct observation research, there is either not enough information provided to devise standard observation practices (e.g., Sudnow, 1965), or the process used is too nuanced and involved for broad use (Cunningham \& McElhinny, 1995). Furthermore, in some literature, results of the observations were not made public (e.g., Cunningham \& McElhinny, 1995). To bridge the gap, we examined the medical literature where similar questions and issues have been investigated to gauge the importance of doctor-patient communication (see Mazor et al., 2005; Makoul, 2001). We first asked defense attorneys their perceptions of what contributes to quality communication and the importance of communication for an effective attorney-client relationship. In an exploratory study, we then combine their responses with prior literature to create an "attorney-client interaction" checklist to use in observing, or "shadowing," attorney and client meetings. Lastly, clients were then asked their perceptions of communication with their attorney during this interaction. Using the shadow method allows for an unbiased account of if practices that contribute to quality communication are being used in interactions. Moreover, how those factors are perceived by clients (i.e., “consumers"). This pilot study fills a critical gap in our understanding of communication between attorneys and clients, by shadowing their meetings, and hearing from both perspectives on the factors that contribute to quality communication.

\section{Structured Shadow Method}


Much of the existing research stresses the importance of communication and supports what has been termed a client-centered approach to lawyering. This research has largely focused on post-hoc surveys/interviews of lawyers and their clients. Additionally, while extant research has emphasized the importance of communication, few studies have offered ways of conceptualizing and operationalizing quality communication. For example, clients who reported that their attorneys listened to them were more satisfied with their attorney overall (Campbell et al., 2015). Yet, concluding that listening equates to satisfaction is problematic (Moore et al., 2018). Without observing those interactions, it is impossible to know what contributed to those perceptions, or how much the attorney and client actually communicated. Direct observation gets at the substance of these interactions, offering data unavailable by any other method (Moore et al., 2018). Moreover, beyond the operationalization of such communication, more direction in designing direct observation studies to collect such data is needed. Subsequently, this project had multiple goals: (1) to extend our knowledge base in this area and contribute to the questions: What does client-centered communication look like? and What factors are important for effective attorneyclient communication?; (2) conceptualize and operationalize a way to capture quality communication between attorneys and their clients; and (3) devise a method by which researchers might collect data using such operationalization. These goals were achieved in a two-phase, multifaceted project that collected information from both public defenders and clients, and relied on surveys and non-participant observations of live communication.

\section{Study Procedure}

This study was designed as an exploratory study to determine the importance and presence of quality communication in criminal defense, as well as a test of innovative data collection methodologies. Partnering with one of multiple firms that provide public, criminal defense in a 
moderately large, western city, the study consisted of a multi-phase, sequential design where the first phase data collection informed the second phase. Phase I involved an attorney questionnaire sent to public defenders working for the public defense firm. After analyzing the information gathered from the attorneys, we then constructed two additional data collection instruments to be used in Phase II, which involved attorney-client communication observation and subsequent client feedback. All study materials (surveys and the checklist) are included in Appendix Materials.

\section{[Insert Figure 1 here]}

\section{Phase I: Attorney Questionnaire}

Consistent with Moore et al.'s (2018) point that research in the area of communication needs to begin with conceptualizing "good" communication (p. 788), Phase I involved an online survey sent out to defense attorneys. The survey consisted of 55 items, generally assessing communication with clients, the typical content of these interactions, the attorney-client relationship, effective communication, and demographic information such as political and religious affiliation. These items were informed by and used in past research on attorney-client communication (Campbell et al., 2015; Raaijmakers et al., 2015; Sandys \& Pruss, 2017; Sunshine \& Tyler, 2003). Participant attorneys were also asked about factors that they think are important in developing and maintaining good communication with their clients. And lastly, participant attorneys responded to questions regarding what they hope to accomplish (objectives or goals) in terms of good communication. All responses were general, and did not ask attorneys any specific/identifying information about cases. ${ }^{1}$

\footnotetext{
${ }^{1}$ We asked for both the attorney's perceptions of themselves, but also that of the office overall because it was an effort to gather as much information as possible regarding varying degrees of practice especially with those who may want to distance themselves from the actions of the whole. Additionally, such information provides insight regarding common informal practices among attorneys who may not be completing the survey, and thus a more well-rounded conception of practices in the office in spite of the lower response rate.
} 


\section{Phase II: Attorney/Client Shadowing}

Using the direction provided by both prior literature (e.g., Mazor et al., 2005; Makoul, 2001) and the information given by the participant attorneys on quality representation and communication, we constructed a checklist to help systematically guide the observation portion of the study. Checklist items were devised so that they could be used to gauge the presence of certain components that are directly observable in an interaction between an attorney and her/his client. The checklist became the basis of Phase II which consisted of two different parts: Shadowing attorney-client interactions (Part A) and collecting a client questionnaire (Part B).

Phase II-Part A. This part of Phase II consisted of research assistants "shadowing" six volunteer attorneys' meetings with their clients. The research assistants were three criminology and criminal justice master's students (post-graduation) and one, second-year law student. ${ }^{2}$ To maximize the reliability and validity in measurement, and confidentiality of the attorney-client interactions, the research assistants were trained on observing communication and how to use the checklist, and signed non-disclosure agreements. Direct observation of attorney-client meetings comes with the unique challenge of protecting confidentiality and privilege, due to the injection of a third-party into the discussions (Moore et al., 2018). After discussions with general counsel of [blinded for review] University, it was determined that the researchers needed to become official interns of the public defense agency to be considered part of the defense team (similar to steps taken by Gonzalez Van Cleve, 2017 and Clair, 2020). ${ }^{3}$ This makes the case that attorney-client confidentiality would not be breached, therefore protecting both the defense attorney and research

\footnotetext{
${ }^{2}$ We realized that with a highly structured instrument to guide observations, law students might be best suited to be part of a defense team, and help in conducting this study. An effort was made to connect with law schools in the area of the firm to recruit more law students, however, we were unsuccessful.

${ }^{3}$ It is worth noting that the partnering agency did not believe this was a necessary step, but was happy to accommodate our request, indicating that it was not a problem to include the assistants as interns.
} 
assistant from being susceptible to subpoena by the prosecution or other defense lawyers (e.g., a co-defendant situation, ineffective assistance of counsel appeal).

The observation procedure relied on coordination with the volunteer attorneys. ${ }^{4}$ Each week the research assistants attempted to connect directly with the volunteer attorneys to determine where and when a client meeting would take place. Due to the nature of many meetings with clients (e.g., difficulty of ensuring a client will be available at a given time when in custody, or not cancel when not in custody) as well as the availability of research assistants, adequate coordination became the single greatest barrier to obtaining observations. Such accessibility barriers have been observed in other jurisdictions as well (see Moore et al., 2019). Unfortunately, this resulted in just 11 meetings being observed. It has been noted that recruiting participants (attorneys and clients) for direct observations studies, such as the one used here, can be difficult because the nature of including a third party dissuades participation (Moore et al., 2018). In this study, lower sample size was more attributable to logistical challenges, and less to attorney lack of willingness to participate. However, as this was a pilot study to examine the overall methodology (attorney survey, shadowing, client survey), sufficient data was collected to draw conclusions about how this approach could be useful to researchers and agencies alike.

Once a meeting was scheduled, the research assistant met with the attorney at the meeting's location, and observed communication contingent on the willingness of all participants (i.e., consent given by the attorney and client). ${ }^{5}$ Research assistants filled out the interview checklist as

\footnotetext{
${ }^{4}$ The study was announced to the attorneys by the agency's director during a staff meeting. The director noted that participation was encouraged, but strictly voluntary. Several attorneys indicated they were happy to take the survey. With the voluntary nature of participation, seven attorneys indicated they were interested in participating in the shadow portion, but one had to be removed from the potential sample because they were working juvenile caseloads.

${ }^{5}$ To ensure the client's consent was obtained while minimizing concern of coercion, we asked the defendants' consent three times prior to administering the questionnaire. First, we had the attorney ask the client's consent in advance of the meeting (over the phone). Then the client was asked again at the start of the meeting. Finally, the client was asked one last time before being administered the survey, after the attorney left the room.
} 
they observed the extent to which the checklist behaviors were present in the interaction between attorney and client. The checklist began with demographics of the case (see the pre-interview checklist in the Appendix). For example, the type of crime and level of the charge, if the client had ever been diagnosed with a mental health disorder, how many contacts the attorney had with that specific client, among other basic case information. The questions were few and non-descriptive so as not to make the client identifiable or capture any case specifics. ${ }^{6}$

Research assistants then rated the degree of presence of various components on a 3-point scale; 1- Not at all, 2-Partially, and 3-Completely (in addition research assistants could indicate, 0- Unknown, if the extent to which the presence of an item indistinguishable to them during the interaction). The checklist items fall into six distinct themes; examples of checklist components within each theme are listed below in Table 1. Each of our themes coincided with the communication factors found by Sandys and Pruss (2017), with the exception of one, which we could not account for with observing one interaction (whether the attorney followed through on what they said).

[Insert Table 1 here]

The full 30-item interview checklist is broken down in Table 2. The first few observations were conducted by all the research assistants (two at each meeting, with four assistants total) at once, after which their checklists were assessed for interrater consistency, with any discrepancies discussed. After three observations were conducted it was clear that there was between $98 \%$ and $100 \%$ agreement; after that point, the assistants observed interactions on their own.

\footnotetext{
${ }^{6}$ This basic case information was collected by the research assistant by asking the attorney for specific information before entering the meeting. It was collected to provide a baseline point of comparison between certain cases. Due to the sample size, such comparisons could not be made. However, future research should capture this information so that nuanced differences in cases with differing degrees of case strengths and circumstances may be compared for communication differences. Information on mental health and chemical dependency was also collected, but kept as dichotomous flags and never linked to a defendant's identifying information.
} 
Phase II-Part B. To ensure more conceptual clarity as highlighted by Moore et al (2018), the final part of this project involved the research assistants administering a survey to the client (i.e., defendant) immediately after the meeting concluded and the attorney left the room. Clients were assured that their attorney would never see any of their answers to the completed survey. Following clients' consent to complete the survey, they answered 43 questions asking about their thoughts regarding this interaction with their attorney. Participants were asked basic demographic information, their general satisfaction with their lawyer, what they got out of the interaction, and given procedural justice and the attorney-client trust scales (among other measures from prior literature). These items were informed by and used in past research on attorney-client communication, attorney-client trust, and procedural justice more generally (e.g., Boccaccini \& Brodsky, 2002; Campbell et al., 2015; Sandys \& Pruss, 2017). Items were measured using sixpoint Likert scales, ranging from strongly agree to strongly disagree.

\section{Demonstrating Utility of a Shadow Method}

Below, we present the results from our pilot study, separated by each phase (i.e., attorney survey, shadowing, and client survey). As noted above, the overall sample is too low to draw conclusions from these specific data, however these data demonstrate how this type of innovate methodology can be used, and beneficial for researchers and practitioners.

\section{Phase I: Attorney Questionnaire}

In total, 13 of 24 attorneys completed the survey ( 8 women, and 5 men), yielding a response rate for the firm of 54\%. Among the respondents, five were 45 years old or older, 12 identified as White, 10 practiced some type of criminal law prior to being public defender, seven started work with this agency within last 10 years, six characterize their caseload as being at least $80 \%$ misdemeanors, and seven report contacting their client at least once every two weeks on average. 
When asked about their perceptions of attorney-client communication, 12 attorneys indicated that they believe communication is at least somewhat important to quality representation, and 11 believe it is at least somewhat important for achieving positive outcomes in the case. Similarly, 11 respondents believe that the attorney-client relationship is at least somewhat important to quality representation, while nine believe it is at least somewhat important for achieving positive outcomes. Lastly, eight attorneys believe that the case outcome is important to achieve client satisfaction with the attorney's performance, while two noted it as not important. Those attorneys who responded that communication and the attorney-client relationship are important also tended to perceive that their clients are satisfied with their job performance.

Beyond the closed-ended questions, responding attorneys were asked questions that were designed to explore how attorneys view quality representation and communication. Specifically, we asked how they would define quality representation, and what the critical components might be. After compiling the responses, we constructed a word cloud based on how often certain words were used by attorneys to describe what they believe is quality representation.

[Insert Figure 2 here]

As can be seen in this figure, some of the most prevalent words used to describe quality representation include terms like "client," "understand," and "communicate," which largely embody client-relational skills as described in prior literature. These words appear just as often, if not more, than words that are most associated with legal skills such as "law," "trial," and "result." These results suggest that attorneys think of communication as a key consideration of quality representation. Some examples of how these words were used and relate to communication, include the following (italics added for emphasis):

- "Establish the trust, understand the client's goals, communicate their options to them so they understand, get the best results possible in line with those goals." 
- "Client feels represented and you know you did your best as to listening, advising, investigating, and advocating."

- "Advocacy, effective communication of a client's viewpoint, an ability to understand and conder all defenses available and then to communicate them to client in a way that allows them to make the best decision. Staying current on the law."

- "Consideration of client's needs and wishes, full disclosure to client, superior knowledge of law, legal system and unwritten county rules, well developed trial skills."

- "Communication both with client as well as court and state, knowledge of the subject matter, knowledge of the working of "the system"."

Participating attorneys were also asked to conceptualize quality communication and its critical components. From their responses, we again made a word cloud based on the frequency of word occurrence (see Figure 2). Like the definitions provided for quality representation, responses largely centered on "client," "listening," "explain," and "understanding." These terms largely coincide with the importance of client-centered aspects of the attorney-client relationship found and used in prior research. Example responses involving these words include the following:

- "Willingness to listen (both attorney and client), taking the time to explain and understand a concept or position (again both attorney and client)."

- "Listen, reflect what you hear, advise, empathize."

- "Number of contacts with client, time spent with client, feedback from client on whether they "heard it"."

- "The ability to understand another person's viewpoint and truly consider it. To listen and validate."

- "Quantity definitely does not equal quality. Trust between attorney and client, and client being honest and attorney listening."

- "Frequent contact and availability, clear explanations of law and options."

\section{Phase II-Part A: Shadowing of Attorney-Client Interaction}


In looking at the data from shadowing attorney-client interactions, nine of the eleven observed meetings were the first in-person meeting the attorney had with the client, and none had been represented by the attorney prior to this case. The other two indicated this was the second or third meeting. ${ }^{7}$ Among the observed meetings, the cases involved six felony charges, four charges for violent crimes, four for property crimes, and two for drug charges. ${ }^{8}$ Four were cases in which the attorney was planning to consult with a caseworker for the client due to a mental health disorder or chemical dependency issue. In all, the aim to capture qualitative elements of attorney-client communication was rather successful. Some variation was observed regarding the degree to which each component was present in the discussions. Overall, the observed interactions presented several elements deemed important by prior research (e.g., Moore et al., 2019), such as providing the clients with an opportunity to voice their perspective (i.e., allowing the client to tell her/his side of the incident), and the attorney defining any legal jargon used. Observations only noted a few instances where a component was not present at all. Only one component was missing just as often as it was present - whether the attorney asked the client what her/his short-term goals were for the case (e.g., out on bail, shortened detention). While our research is exploratory in nature, see Table 2 for the frequency of each item within the taxonomy of quality communication factors (Sandys \& Pruss, 2017) and the six themes we divised from the prior research on attorney-client communication (e.g., Campbell et al., 2015) and the medical bed-side literature (Makoul, 2001; Mazor et al., 2005).

[Insert Table 2 here]

\section{Phase II-Part B: Client Survey}

\footnotetext{
${ }^{7}$ Ideally, the shadowing method, complete with the checklist and client survey would be best suited for the initial meeting between the client and attorney. This is because it is arguably the most important one where a new client, who is potentially in their first contact with the justice system, is gauging what this relationship might yield and how to act in response to the attorney's demeanor and questions.

${ }^{8}$ Across the 11 cases, there were a few cases that had multiple charges.
} 
Two clients refused to participate in the survey, resulting in nine surveys, of which one was only partially completed. Clients ranged in age from 19 to 62 years old, five were male, six identified as White, and all but one had a high school education or more. Of the seven who answered the question regarding satisfaction with their lawyer, all seven indicated that they were very satisfied. See Table 3 for select components from the survey. For the purposes of reporting here, we dichotomized the response options into agree or disagree. Most notable is that clients largely felt as though they had a good communication with their attorney. Only a few components did not receive full or nearly full support. For instance, a few surveyed clients indicated a belief that if they had the ability to hire a private attorney, they would likely receive better representation and overall outcome. Five of the eight respondents also indicated that they did not believe their lawyer liked them as a person, however, seven noted that they liked their attorney.

[Insert Table 3 here]

\section{Discussion and Lessons Learned}

In 2004, the American Bar Association highlighted how the promises of Gideon were largely unmet, pointing to issues in funding, caseload pressures, and lack of training and adequate pay for attorneys. The American Bar Association called for more research on the topic of indigent defense, and pointed to the importance of attorney-client communication in reforming the indigent defense system (2004; Sandys \& Pruss, 2017). This work builds on that call by examining attorney communication using an innovative methodology structure - shadowing. Although the sample size was too small to examine the observations in more complex ways, the study yielded a number of other elements that are important for the goals of this project, future research, and practitioners/agencies interested in improving their attorney-client relationships. First, the goals of the study aimed to extend our knowledge base in the area of attorney-client communication by 
way of conceptualizing and operationalizing client-centered communication. Combined findings from our attorney and client survey, as well as findings from the literature, suggest that perhaps a way to conceptualize quality communication may be the following:

Quality attorney-client communication establishes trust, through listening to and identifying the client's needs, and translating them into viable, legal options that involve potential outcomes and are understandable for the client. Such communication involves attentive and empathic listening, while also providing realistic legal advice and an action plan for the case that involves demonstratable objectives for investigating and advocating for the client. The communication should always end with a summary of the plan, next steps for the court's process, when the next meeting will be, and how to contact one another.

In a similar vein, responses regarding overall quality representation reverberated common traits found in the literature. Again, using our survey findings coupled with the literature, our process seemed to suggest that a way to conceptualize quality representation may be the following:

Quality representation involves the ability of the attorney to provide the best legal advice possible, given (first) the confines of the client's short-and long-term goals and needs, and (second) the contextual aspects of the case, law, and possible options. Quality representation inherently relies on developing rapport through trust, honesty, and fostering adequate frequency of quality attorney-client communication.

Together, effective, quality communication provide the basis from which we can begin to determine the factors that contribute to quality representation. The factors important to effective communication are those that foster attorneys' abilities to listen, allow room for client participation and voice, provide ample and contextual advice, and empathize with client positions and perspectives. This research is supportive of other research focusing on communication and client satisfaction (Moore et al., 2019; Sandys \& Pruss, 2017). While attorneys have unique communication styles, appropriate resources (time and reasonable work/caseloads) and specialized training (e.g., in holistic defense, and procedural and social justice best practices), can pave the way towards institutionalizing stronger attorney-client relationships. 
Second, this project aimed to operationalize approaches and devise a method to better capture quality communication. Since Sudnow's 1965 study, few studies have involved direct observation of attorney-client interactions (Clair, 2020; Goldsmith, 1980; Gonzalez Van Cleve, 2016; Sarat \& Felstiner, 1989), and the majority involved civil cases, or made no mention of the ethics involved in observational research. Nonetheless, these studies reveal important details about attorney-client communication that would have been unknown without observational methodologies (Moore et al., 2018), underscoring the need for shadowing-type approaches. For example, attorney interruptions shut down conversations, while open-ended questions are more effective (Goldsmith, 1980 as cited in Moore et al., 2018). Some studies have addressed the concern of third parties and forced disclosure (Cunningham \& McElhinny, 1995; Neustadter, 1986), with the best suggestion being to include the researcher as part of the defense team, which maintains confidentiality and communication privilege. As such, this method was used in the current study, to allow for direct observation between clients and public defenders, in addition to capturing their perspectives through targeted surveys. Work involving direct observations should consider including the researcher as a member of the defense team (recommended by Cunningham \& McElhinny, 1995), focus on low-level cases, and even include a signed agreement from the prosecution that prohibits access to information collected for the purposes of the study (recommended by Moore et al., 2018). This also places a responsibility on the judicial bench to protect and promote such research (Moore et al., 2018).

In this paper, we hope to have provided researchers and practitioners with an additional mechanism of measuring the effectiveness of attorney-client communication-shadowing meetings using literature-driven, systematic observation. This type of observation comes with challenges and concerns, and should be undertaken in conjunction with necessary partners (e.g., 
university ethics office, university lawyers). That said, this type of observation allows researchers and perhaps third-year law students to examine the interaction between client and attorney in a more objective manner, rather than only relying on attorney or client perspective recall of the interactions. These tools synthesize indicators of "good" communication strategies and behaviors, provide a method to measure them (checklist), and allow for a mixed methods approach to examining attorney-client communication through observations and surveys of the both parties. Our hope for this manuscript and its accompanied data collection tools is that they be useful for agencies and researchers to apply in their own jurisdictions/settings to help gauge their own practice and build on what is known by gaining more observations. This approach provides a distinct advancement on how we gather data on attorney-client interactions and communication from prior studies by providing a triangulated method of collecting these data. By using this method, we are able to shed light on a previously unknown area of knowledge in how an attorneyclient interaction might be perceived and what information is derived from such important conversations. We encourage agencies and researchers alike to use and modify our instruments in ways that are scientifically sound and helpful to their specific goal.

\section{Need for More Research}

We support the calls by legal scholars (e.g., Moore et al., 2019) for more research on the attorney-client relationship, specifically communication. As mentioned in the introduction of this manuscript, public defense attorneys face obstacles different from those in the private sector. For example, in a 2013 Florida Supreme Court case, the court ruled that excess caseloads, work restrictions, and inadequate funding were acceptable bases to withdraw as counsel (Public Defender, Eleventh Judicial Circuit of Florida, et al. v. State of Florida, 2013). Future research in this area should explore the effects of situational constraints facing public defenders in light of 
cuts to indigent defense budgets. Considering public defense budgets pale in comparison to prosecutors' offices ( $\$ 5.8$ billion annually for prosecutor offices compared to $\$ 2.3$ billion for public defender offices; Langton \& Farole, 2010; Perry \& Banks, 2011), it is clear that future research (and the general public) must consider the systemic challenges that influence the role and work of public defenders. Using the operationalized processes and measures we provide here along with workload data, agencies can forecast the potential effects of budgetary or resource changes and identify areas of greater need. Moreover, semi-regular data collection and aggregate reporting of the themes and items presented here can provide agencies with the ability to track relationships over time, thereby potentially demonstrating a clear link between sparse resources and its effect on attorney-client communication and an agency's ability to provide quality representation.

Future work should also continue to examine the content of attorney-client communication in considering its effectiveness. This is particularly relevant in light of systemic constraints, because more is not always better (i.e., it is about quality, not quantity). For example, recent research on a sample of juvenile offenders waived to adult court in NYC, found that the majority of participants reported infrequent contact with their attorney (the majority represented by public defenders; Zottoli et al., 2016). Relevant to the research on attorney-client communication, a natural question here is - what was the content and quality of those interactions? What were clients' perceptions of those meetings? Defense attorneys' perceptions? Shadowing interactions, or other innovative methodologies such as the one used here, can help to address these questions and contribute to our understanding of the attorney-client relationship. Although, importantly, direct observation does not allow for making any inferences about motivations of the attorney or client (Moore et al., 2018). 
Regardless of the qualitative research method used to capture attorney-client communication and interactions, in addition to the ethical concerns, researchers must be cognizant of threats to validity such as the Hawthorne effect and selection bias. With regard to the Hawthorne effect, it is feasible that attorneys being observed for their skills and communication may alter their behavior to be more in line with what they think is desirable. One potential option is to have attorneys audio- or video-record interactions with their clients for the course of a month or more. Barring appropriate storage of sensitive recordings, this would ensure that there is no third party present, provide a larger pool of qualitative observations, and provide a way to monitory differences within attorney-client pairs over time. An important caveat is if the researcher is not part of the defense team, then such recordings must be relinquished to a researcher after the case is concluded in order to maintain attorney-client privilege. Additionally, such recordings could be used to help coach attorneys, similar to some methods of improving communication between probation officers and their clients (see Smith et al., 2012). Such recording may also work in terms of selection bias so long as it is a top-down request or mandated by the partnering agency. If the agency can push to ensure that there will be a random recording on any given attorney-client meeting, a self-selection bias would no longer be a threat to validity. However, a great deal of caution must be expressed here on the point of client consent and the potential to have recordings subpoenaed by the prosecution. For example, in all meetings, clients would be required to give consent, but recordings would be random, and not occur in all interactions. Under the auspices and aim of improving representation, and the recordings ultimately be erased and de-identified, this concern can be minimized.

\section{Implications for Research, Agencies, and Practice}


Research on clients' perceptions of their attorneys emphasize the importance of quality communication for an effective attorney-client relationship. The research presented in this manuscript also emphasizes the importance of quality communication for attorneys. Attorneys at this agency were cognizant of the importance of quality communication, and their interactions with clients demonstrate that attorneys are implementing factors of quality communication (e.g., allowing the client to speak without interruption). These data support that to the extent they are able, all agencies should to continue to strive towards enforcing and implementing quality communication factors in their meetings with clients.

A recent call for more empirical research on attorney-client communication in public defense emphasized the importance of identifying attorney performance indicators for making the most of limited time with clients and overcoming client trust issues (Moore et al., 2018). The shadowing method with accompanying checklist items, highlight such performance indicators. Many of the items are not time-intensive (e.g., allowing the client to speak without interruption, statements are non-judgmental), and should not greatly lengthen meeting times with clients. Moreover, research has suggested numerous factors of quality, effective communication with clients that do not require financial expenditures (e.g., asking the client their opinion, explaining or avoiding confusing legal jargon), these items are incorporated into the accompanying checklist.

However, implementing some of these strategies take time, a luxury most public defense attorneys do not have. Therefore, we would also recommend documenting where systemic challenges prevent attorneys from engaging in quality communication with clients. Doing so, can help shed light on where these challenges are most likely to manifest, which will allow for a targeted discussion of solutions. This checklist can be used as a performance indicator for attorneys, helping to shed light on areas of improvement in their communication with clients. 
Overall, the instruments included here may be beneficial for researchers, public defense agencies looking to examine their attorneys' interactions with clients (in a more systematic manner), and as a training/educational tool for new lawyers and law students (e.g., recording student-client conferences for education purposes in law clinics; Smith, 2018). As noted by Moore and colleagues (2018), information gained "could inform rights-information and satisfaction-feedback tools to tap perspectives and promote effective reform-oriented community organizing among people who need public defense" (p.781-782, also citing Walker, 2009). Ultimately, this project demonstrates how a mixed method approach, utilizing direct observation, could help measure and ultimately, improve communication between public defenders and their clients; however, carefully consideration of privilege, confidentiality, and client privacy must remain at the forefront of these endeavors. 


\section{References}

Agency for Healthcare Research and Quality. (2005). National Helthcare Quality Report (No. 06-0018). U.S. Department of Health and Human Services.

American Bar Association, 2004. Gideon's broken promise: America's continuing quest for equal justice. Retrieved from

https://www.americanbar.org/content/dam/aba/administrative/legal_aid_indigent_defenda nts/ls sclaid def bp right to counsel_in_criminal proceedings.authcheckdam.pdf

American Bar Association. (2015). ABA criminal justice standards for the defense function, 4th ed. Retrieved from

https://www.americanbar.org/groups/criminal_justice/standards/DefenseFunctionFourthE dition.html\#1.2

Barton, K., Cunningham, C. D., Jones, G. T., \& Maharg, P. (2006). Valuing what clients think: Standardized clients and assessment of communicative competence. Clinical Law Review, 13(1), 1-66.

Beeman, M. (2018). National Indicators of Quality Indigent Defense. Washington, DC: National Legal Aid \& Defender Association. Retrieved from http://www.nlada.org/sites/default/files/pictures/2018-0308\%20Quality\%20Indicators $\% 20$ Project $\% 20$ covered.pdf

Boccaccini, M. T., Boothby, J. L., \& Brodsky, S. L. (2004). Development and effects of client trust in criminal defense attorneys: Preliminary examination of the congruence model of trust development. Behavioral Sciences and the Law, 22, 197-214.

Boccaccini, M. T., \& Brodsky, S. L. (2001). Characteristics of the ideal criminal defense attorney from the client's perspective: Empirical findings and implications for legal practice. Law and Psychology Review, 25, 81-117.

Boccaccini, M. T., \& Brodsky, S. L. (2002). Attorney-client trust among convicted criminal defendants: Preliminary examination of the attorney-client trust scale. Behavioral Sciences \& the Law, 20, 69-87. https://doi.org/10.1002/bsl.469.

Campbell, C. M., Moore, J., Maier, W., \& Gaffney, M. (2015). Unnoticed, Untapped, and Underappreciated: Clients' Perceptions of their Public Defenders. Behavioral Sciences and the Law, 33(6), 751-770. doi:10.1002/bs1.2182.

Clair, M. (2020). Privilege and punishment: How race and class matter in criminal court. Princeton University Press.

Cunningham, C. D. (1998). Evaluating Effective Lawyer-Client Communication: An International Project Moving from Research to Reform Special Issue: Conference on the Delivery of Legal Services to Low-Income Persons: Professional and Ethical Issues. Fordham Law Review, 67(5), 1959-1986. 
Cunningham, C. D., \& McElhinny, B. S. (1995). Taking It to the Streets: Putting Discourse Analysis to the Service of a Public Defender's Office Work-in-Progress. Clinical Law Review, 2(1), 285-314.

Davis, K. (1976). Discretionary Justice: A Preliminary Inquiry (Fifth Printing edition). University of Illinois Press.

Drinan, C. H. (2010). The National Right to Counsel Act: A Congressional Solution to the Nation's Indigent Defense Crisis. Harvard Journal on Legislation, 47(2), 487-522.

Gellhorn, G., Robins, L., \& Roth, P. (1994). Law and Language: An Interdisciplinary Study of Client Interviews. Clinical Law Review, 1(2), 245-298.

Gerber, R. J. (1989). Lawyers, Courts, and Professionalism: The Agenda for Reform. Greenwood Publishing Group.

Gideon v. Wainwright, 372 US 335 (Supreme Court 1963).

Goldsmith, J. D. (1980). The initial attorney/client consultation: A case history. Southern Speech Communication Journal, 45(4), 394-407. https://doi.org/10.1080/10417948009372467

Gonzalez Van Cleve, N. (2017). Crook County: Racism and Injustice in America's Largest Criminal Court (1 edition). Stanford University Press.

Harlow, C.W. (2000). Defense Counsel in Criminal Cases. Bureau of Justice Statistics Special Report. Retrieved from: http://www.bjs.gov/index.cfm?ty=tp\&tid=28

Hoff, T. J., Pohl, H., \& Bartfield, J. (2006). Teaching but not learning: How medical residency programs handle errors. Journal of Organizational Behavior, 27(7), 869 896. https://doi.org/10.1002/job.395

Hosticka, C. J. (1979). We Don't Care about What Happened, We Only Care about What Is Going to Happen: Lawyer-Client Negotiations of Reality. Social Problems, 26(5), 599610. https://doi.org/10.2307/800044

Institute of Medicine (US). (2001). Crossing the Quality Chasm: A New Health System for the 21 st Century - Institute of Medicine. National Academies Press. http://www.iom.edu/Reports/2001/Crossing-the-Quality-Chasm-A-New-Health-Systemfor-the-21st-Century.aspx

Kohnke, W. R. (2001). Professionalism in corrections. American Jails, 15(1), 75-78.

Langton, L., \& Farole, Jr. D. (2010). State public defender programs, 2007. U.S. Department of Justice, Office of Justice Programs, Bureau of Justice Statistics. Retrieved from https://www.bjs.gov/content/pub/pdf/spdp07.pdf 
Makoul, G. (2001). The SEGUE framework for teaching and assessing communication skills. Patient Education and Counseling, 45, 23-34.

Mazor, K. M., Ockene, J. K., Rogers, J., Carlin, M. M., \& Quirk, M. E. (2005). The Relationship between Checklist Scores on a Communication OSCE and Analogue Patients'

Perceptions of Communication. Advances in Health Sciences Education, 10, 37-51. DOI: 10.1007/s10459-004-1790-2.

Missouri v. Frye, 566 U.S. 134 (2012).

Moore, J., \& Davies, A. L. B. (2016). Knowing Defense Symposium: Public Defense: Critical Issues and New Empirical Research. Ohio State Journal of Criminal Law, 14(2), 345372.

Moore, J., Plano Clark, V. L., Foote, L. A., \& Dariotis, J. K. (2019). Attorney-Client Communication in Public Defense: A Qualitative Examination. Criminal Justice Policy Review, 1-31. https://doi.org/10.1177/0887403419861672.

Moore, J., Yaroshefsky, E., \& Davies, A. L. B. (2018). Privileging public defense research. Mercer Law Review, 69, 769-802.

Mezey, M. D., \& Mitty, E. (2011). A Bill of Rights for Hospitalized Older Adults. JONA: The Journal of Nursing Administration, 41(3), 115-121. https://doi.org/10.1097/NNA.0b013e31820c722d

Neustadter, G. (1986). When Lawyer and Client Meet: Observations of Interviewing and Counseling Behavior in the Consumer Bankruptcy Law Office. Buffalo Law Review, 35(1), 177-284. Available at SSRN: https://ssrn.com/abstract=2731317

Perry, S. W., \& Banks, D. (2011). Prosecutors in state courts, 2007-Statistical tables. U.S. Department of Justice, Office of Justice Programs, Bureau of Justice Statistics. Retrieved from https://www.bjs.gov/content/pub/pdf/psc07st.pdf

Padilla v. Kentucky, 559 U.S. 356, 366-67 (2010).

Public Defender, Eleventh Judicial Circuit of Florida, et al. v. State of Florida, Nos. SC09-1181 and SC10-1349 (2013).

Raaijmakers, E., de Keijser, J. W., Nieuwbeerta, P., \& Dirkzwager, A. J. E. (2015). Criminal defendants' satisfaction with lawyers: Perceptions of procedural fairness and effort of the lawyer. Psychology, Crime \& Law, 21(2), 186-201. https://doi.org/10.1080/1068316X.2014.951646

Sandys, M. \& Pruss, H. (2017). Correlates of Satisfaction Among Clients of a Public Defender Agency. Ohio State Journal of Criminal Law, 14(2), 431- 461. 
Sarat, A., \& Felstiner, W. L. F. (1989). Lawyers and Legal Consciousness: Law Talk in the Divorce Lawyer's Office. The Yale Law Journal, 98(8), 1663-1688. https://doi.org/10.2307/796611

Shaller, D. (2007). Patient-Centered Care: What does it take? The Commonwealth Fund, The Picker Institute. http://www.commonwealthfund.org/ /media/Files/Publications/Fund\%20Report/2007/Oc t/Patient $\% 20$ Centered $\% 20$ Care $\% 20 \% 20$ What $\% 20$ Does $\% 20 I t \% 20$ Take/Shaller_patient $\%$ 20centeredcarewhatdoesittake 1067\%20pdf.pdf

Sklansky, D. A. (2011). The Persistent Pull of Police Professionalism. Harvard Kennedy School Program in Criminal Justice Policy and Management.

Smith, L.F. (2018). Rx for teaching communication skills: Why and how clinicians should record, transcribe and study actual client consultation. Clinical Law Review, 487-531. https://www.law.nyu.edu/sites/default/files/upload_documents/Linda $\% 20 \mathrm{Smith} \% 20 \mathrm{re} \% 2$ 0Rx\%20for\%20Teaching\%20Communication.pdf

Smith, P., Schweitzer, M., Labrecque, R. M., \& Latessa, E. J. (2012). Improving probation officers' supervision skills: An evaluation of the EPICS model. Journal of Crime and Justice, 35(2), 189-199.

Steinberg, R. (2013). Heeding Gideon's Call in the Twenty-First Century: Holistic Defense and the New Public Defense Paradigm. Washington and Lee Law Review, 70, 961.

Stewart, M., Brown, J. B., Donner, A., McWhinney, I. R., Oates, J., Weston, W. W., \& Jordan, J. (2000). The Impact of Patient-Centered Care on Outcomes. Journal of Family Practice, 49(9), 796-804.

Sudnow, D. (1965). Normal Crimes: Sociological Features of the Penal Code in a Public Defender Office. Social Problems, 12(3), 255-276. JSTOR.

Sunshine, J., \& Tyler, T. R. (2003). The Role of Procedural Justice and Legitimacy. Law \& Society Review, 37(3), 513-548.

Walker, D. W. (2009). Citizen-Driven Reform of Local-Level Basic Services: Community-Based Performance Monitoring. Development in Practice, 19(8), 1035-1051.

Walker, S. (1993). Taming the System: The Control of Discretion in Criminal Justice, 19501990. Oxford University Press.

Zottoli, T. M., Daftary-Kapur, T., Winters, G. M., \& Hogan, C. (2016). Plea discounts, time pressures, and false guilty pleas in youth and adults who pleaded guilty to felonies in New York City. Psychology, Public Policy, and Law, 22(3), 250-259. 
Table 1. Six checklist themes alongside Sandys and Pruss (2017) factors

\begin{tabular}{|c|c|c|}
\hline Theme & Checklist components (item examples) & Sandys and Pruss factors \\
\hline $\begin{array}{l}\text { 1. Client } \\
\text { involvement in } \\
\text { case }\end{array}$ & $\begin{array}{l}\text { a. Asked client about his/her ideas and feelings } \\
\text { about the plan for the case (e.g., "What do you } \\
\text { think we should do?" or "How would you like } \\
\text { to proceed?"). } \\
\text { b. Encourages client questions about the case } \\
\text { (e.g., asks if has any questions, allows time to } \\
\text { discuss questions). }\end{array}$ & None equivalent \\
\hline
\end{tabular}

a. Explores client's contextual factors to the incident which may be relevant for the case

2. Explores (e.g., family, peers, situation).

clients' needs

b. Asked the client what his/her short-term goals are for the case (e.g., out on bail, shortened detention, maintain current job, visitation with kids/family).

None equivalent

a. Attorney's statements appear to be nonjudgmental (e.g., is not condescending).

My lawyer treated me with

3. Respect for client

respect

a. Explains jargon or legal terms that could be unfamiliar.
4. Effective Communication
b. Check to make sure client understands (e.g., "Is that clear?" or "Do you have any questions?").
c. Allowed client to speak without interruption.

My lawyer said confusing things

My lawyer interrupts me when I'm speaking

a. Makes statements of partnership, use the word "we" to indicate that he/she will work with the

5. Commitment to
Client client.

My lawyer explained what was

b. Establishes plan and/or method of contacting going to happen next each other (e.g., "Here's what to do if you want to get ahold of me...").

a. Provides client what $\mathrm{s} /$ he thinks is the best course of action (e.g., "Here's what I think we should do...").

6. Advisement

b. Attorney discussed more than one way to approach the case with the client (i.e., attorney My attorney tells me what gave the client options regarding how to move forward). 
Table 2. Attorney-Client Interview Checklist (Phase II-Part A): Frequency of communication component presence in observed attorney-client interactions $(\mathrm{n}=11)$

\begin{tabular}{|c|c|c|c|}
\hline Communication components & $\begin{array}{c}\text { Not } \\
\text { present }\end{array}$ & $\begin{array}{c}\text { Partially } \\
\text { present }\end{array}$ & Present \\
\hline \multicolumn{4}{|l|}{ Client involvement in the case } \\
\hline Asked client short-term goals for case (e.g., out on bail, shortened detention) & 5 & 3 & 2 \\
\hline Asked client's perspective/story about incident/charge (e.g., What happened?) & 1 & 0 & 10 \\
\hline Asked client feelings about case (e.g., "How would you like to proceed?") & 1 & 5 & 5 \\
\hline Respects client's active participation in decision making & 0 & 3 & 8 \\
\hline Gets client input on the plan (i.e., What client wants to get out of the meeting) & 2 & 3 & 6 \\
\hline \multicolumn{4}{|l|}{ Explores client's needs } \\
\hline Explores contextual factors potentially relevant fo & 0 & 2 & 9 \\
\hline Explores client's needs (e.g., housing, abusive situation, chemical dependency) & 2 & 3 & 6 \\
\hline Asked client needs in moving forward during and/or after this case (e.g., housing) & 3 & 4 & 4 \\
\hline \multicolumn{4}{|l|}{ Treated the client with respect } \\
\hline Attorney's statements appear to be non-judgmental (e.g., is not condescending) & 0 & 0 & 11 \\
\hline \multicolumn{4}{|l|}{ Effective communication, minimize/clarify jargon, and did not interrupt client } \\
\hline Starts with open-ended questions, then moves to close-ended questions & 1 & 4 & 6 \\
\hline Explains jargon or legal terms that could be unfamiliar & 0 & 1 & 10 \\
\hline Check to make sure client understands (e.g., Do you have any questions?) & 0 & 4 & 7 \\
\hline Checked to see if client had any final questions before leaving & 1 & 3 & 7 \\
\hline Repeated client's statements for clarification (e.g.. "If I'm hearing you correctly...") & 1 & 4 & 6 \\
\hline Allowed client to speak without interruption & 0 & 4 & 7 \\
\hline Asked client one question at a time & 0 & 0 & 11 \\
\hline Gave client pieces of information at a time while asking about clarification needs & 0 & 0 & 11 \\
\hline Asked client to be specific in statements (e.g., What do you mean by "recently"?) & 0 & 2 & 9 \\
\hline Use appropriate non-verbal behavior (e.g., eye contact when client is speaking) & 0 & 4 & 7 \\
\hline Tone of voice is friendly but professional (i.e., not hostile or apathetic/robotic) & 0 & 2 & 9 \\
\hline Handled the visit efficiently, was systematic, organized & 0 & 3 & 8 \\
\hline \multicolumn{4}{|l|}{ Commitment to client and clearly explain what is going to happen next } \\
\hline Identifies/enlists other resources to support the case (e.g., potential eyewitnesses) & 2 & 2 & 7 \\
\hline Establishes plan/method of contacting each other & 0 & 3 & 8 \\
\hline Makes statements of partnership, use the word "we" in work with the client & 3 & 3 & 5 \\
\hline At the end of the meeting, summarize important information ("take away" points) & 1 & 5 & 5 \\
\hline At the end of the visit, makes clear what the next steps are & 0 & 2 & 9 \\
\hline \multicolumn{4}{|l|}{ Advisement/counseling and tells clients what you are planning to do } \\
\hline Provides thoughts on best course of action (e.g., "What I think we shoulc & 0 & 1 & 10 \\
\hline Discussed multiple possible approaches (i.e., gave options for moving for & 0 & 2 & 9 \\
\hline
\end{tabular}


Table 3. Client Survey (Phase II-Part B): Client perceptions of communication components in attorney-client interactions $(\mathrm{n}=9)$

\begin{tabular}{lcc}
\hline Select communication components & Disagree & Agree \\
\hline I got all the information I needed from my lawyer & 1 & 7 \\
I feel like my questions were answered & 0 & 8 \\
I feel like my lawyer explains all the necessary information (e.g., court dates, procedure) & 0 & 9 \\
I feel like my lawyer listened carefully to what I said & 0 & 9 \\
If I hired my own lawyer, I would get better legal representation & 4 & 3 \\
If I hired my own lawyer, I would probably get a better outcome & 6 & 1 \\
I don't think my lawyer really cares about me as a person & 5 & 3 \\
My lawyer made me feel like we were working as a team & 0 & 9 \\
My lawyer treated me with respect & 0 & 8 \\
My lawyer interrupted me while I was speaking & 7 & 2 \\
My lawyer told me how to get ahold of them if I need to & 0 & 7 \\
I trust my lawyer to make decisions for my best interest & 0 & 9 \\
I like my lawyer & 0 & 7 \\
\hline
\end{tabular}


Figure 1. Phase Progression of the Exploratory Process.

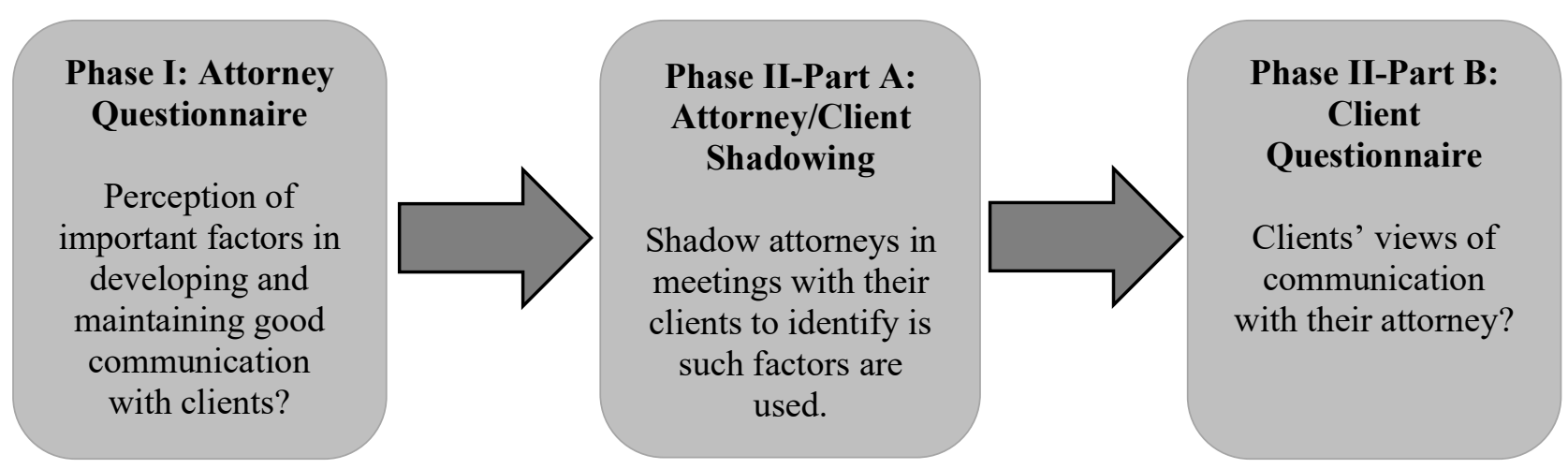


Figure 2. Word Clouds of Responses Describing "Quality Representation” (left) and "Quality Communication' (right)
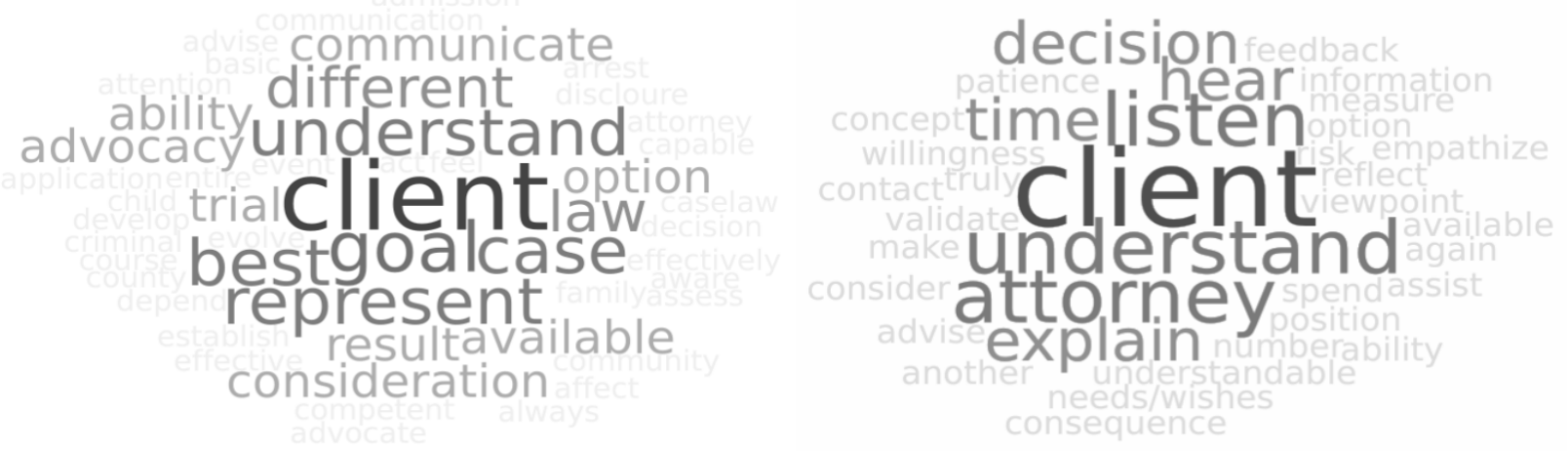